\title{
Origin of defect luminescence in ultraviolet emitting AIGaN diode structures
}

Cite as: Appl. Phys. Lett. 118, 202101 (2021); https://doi.org/10.1063/5.0047021

Submitted: 09 February 2021 • Accepted: 03 May 2021 • Published Online: 17 May 2021

Martin Feneberg, (i) Fátima Romero, (Düdiger Goldhahn, et al.
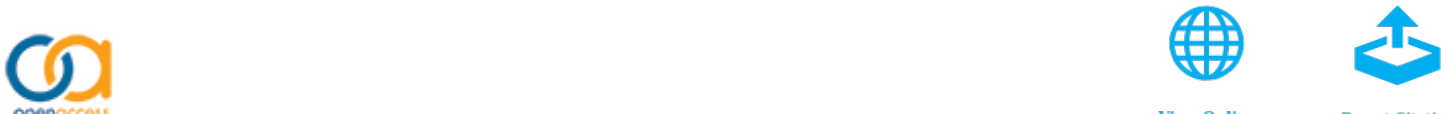

View Online

\section{ARTICLES YOU MAY BE INTERESTED IN}

Ultrawide bandgap semiconductors

Applied Physics Letters 118, 200401 (2021); https://doi.org/10.1063/5.0055292

AlGaN-based UV-B laser diode with a high optical confinement factor

Applied Physics Letters 118, 163504 (2021); https://doi.org/10.1063/5.0046224

MBE growth and donor doping of coherent ultrawide bandgap AIGaN alloy layers on singlecrystal AIN substrates

Applied Physics Letters 118, 092101 (2021); https://doi.org/10.1063/5.0037079

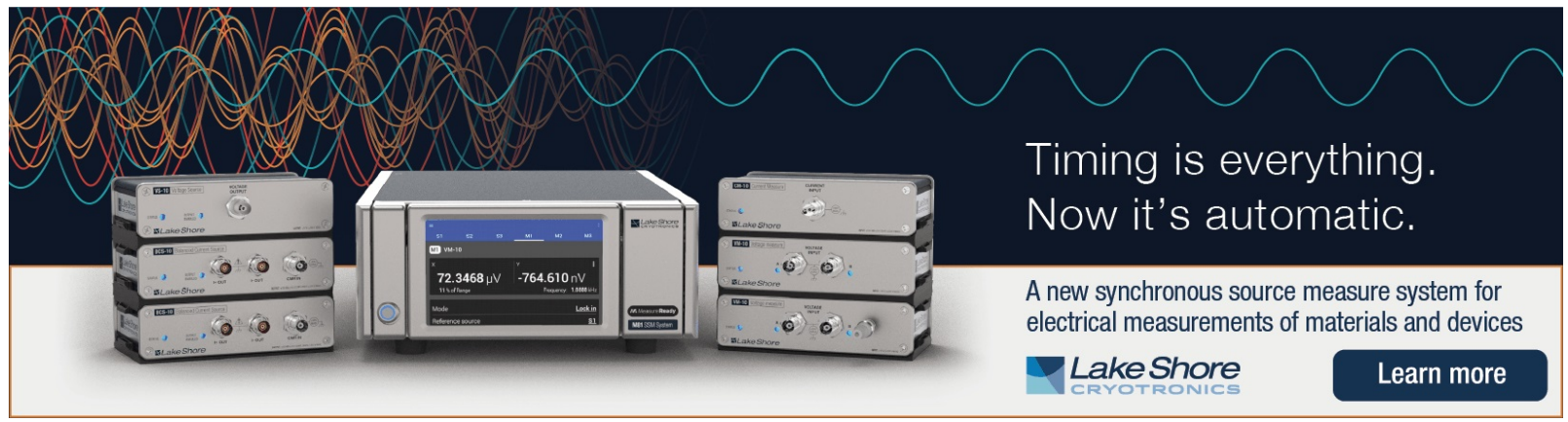




\title{
Origin of defect luminescence in ultraviolet emitting AIGaN diode structures
}

\author{
Cite as: Appl. Phys. Lett. 118, 202101 (2021); doi: 10.1063/5.0047021 \\ Submitted: 9 February 2021 - Accepted: 3 May 2021 • \\ Published Online: 17 May 2021
}

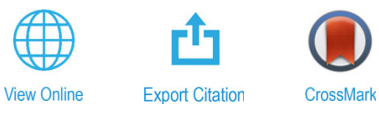

Martin Feneberg, $^{1, a)}$ (D) Fátima Romero, ${ }^{1, b)}$ (D) Rüdiger Goldhahn, ${ }^{1}$ (D) Tim Wernicke, ${ }^{2}$ (D) Christoph Reich, ${ }^{2}$ Joachim Stellmach, ${ }^{2}$ Frank Mehnke, ${ }^{2}$ (D) Arne Knauer, ${ }^{3}$ (D) Markus Weyers, ${ }^{3}$ (D) and Michael KneissI ${ }^{2,3}$ (iD)

\author{
AFFILIATIONS \\ ${ }^{1}$ Institut für Physik, Otto-von-Guericke-Universität Magdeburg, Universitätsplatz 2, 39106 Magdeburg, Germany \\ ${ }^{2}$ Institut für Festkörperphysik, Technische Universität Berlin, Hardenbergstr. 30, 10623 Berlin, Germany \\ ${ }^{3}$ Ferdinand-Braun-Institut gGmbH, Leibniz-Institut für Höchstfrequenztechnik, Gustav-Kirchhoff-Str. 4, 12489 Berlin, Germany
}

a) Author to whom correspondence should be addressed: martin.feneberg@ovgu.de

b) Present address: Universidad Francisco de Vitoria, Carretera Pozuelo a Majadahonda, Km 1.800, 28223 Madrid, Spain.

\begin{abstract}
Light emitting diode structures emitting in the ultraviolet spectral range are investigated. The samples exhibit defect luminescence bands. Synchrotron-based photoluminescence excitation spectroscopy of the complicated multi-layer stacks is employed to assign the origin of the observed defect luminescence to certain layers. In the case of quantum well structures emitting at 320 and $290 \mathrm{~nm}$, the n-type contact $\mathrm{AlGaN}: \mathrm{Si}$ layer is found to be the origin of defect luminescence bands between 2.65 and $2.8 \mathrm{eV}$. For 230 nm emitters without such n-type contact layer, the origin of a defect double structure at 2.8 and $3.6 \mathrm{eV}$ can be assigned to the quantum wells.
\end{abstract}

(C) 2021 Author(s). All article content, except where otherwise noted, is licensed under a Creative Commons Attribution (CC BY) license (http:// creativecommons.org/licenses/by/4.0/). https://doi.org/10.1063/5.0047021

There is a growing demand for ultraviolet light emitting diodes (UV-LEDs) for many different applications like surface polymerization, ${ }^{1}$ gas sensing, ${ }^{2}$ or water disinfection. ${ }^{3}$ Such UV-LEDs became available recently based on wurtzite AlGaN. However, their wall-plug efficiency is very low compared to their visible counterparts. ${ }^{4,5}$ One of the possible reasons for this striking difference in efficiency is discussed to be defects in different functional layers of the UV-LED structure. ${ }^{6}$ This assumption seems reasonable because AlGaN as lightemitting semiconductor material is less optimized compared to InGaN. Some of these defects manifest itself in the form of a broad unstructured defect luminescence band which is frequently observed in UV-LED structures. ${ }^{7,8}$

In this Letter, we contribute to the ongoing discussion by determining the layer from which the defect luminescence originates in AlGaN UV-LED structures. Therefore, we performed photoluminescence excitation spectroscopy experiments on several UV-LED structures. Careful examination of our results shows that the broad band peaking around $2.7 \mathrm{eV}$ stems from the n-type contact layer grown below the quantum wells (QWs) of the UV-LEDs. This result proves that material optimization even of contact layers might contribute to advances in UV-LEDs.

We investigate samples designed for different emission wavelengths: 320,290 , and $230 \mathrm{~nm}$. The selected samples were grown by metal-organic vapor phase epitaxy with (0001) orientation on different buffer/substrate combinations, containing superlattices for strain management, ${ }^{9,10}$ AlN templates defined by epitaxial lateral overgrowth (ELO) on structured sapphire, ${ }^{11}$ and direct growth of $\mathrm{AlN}$ on $\mathrm{Al}_{2} \mathrm{O}_{3}$. ${ }^{12}$

Our set of samples consists of three samples emitting around $320 \mathrm{~nm}$ (sample series A), one sample emitting at $290 \mathrm{~nm}$ (sample B) and two emitting at $230 \mathrm{~nm}$ (series C). Samples A1 and A2 were grown on a $1.3 \mu \mathrm{m}$ thick AlN template on sapphire with a dislocation density estimated to be $5-7 \times 10^{9} \mathrm{~cm}^{-2}$ from omega rocking curve broadening of the $\mathrm{AlGaN}$ (00.2) and (10.2) reflexes followed by an 80-period AlN/ GaN superlattice. Sample A3 was grown on an AlN ELO structure with dislocation density of less than $2 \times 10^{9} \mathrm{~cm}^{-2}$. For all samples of series $\mathrm{A}$, the next layers are $\mathrm{Al}_{0.35} \mathrm{Ga}_{0.65} \mathrm{~N}$ :Si with $\approx 6 \mu \mathrm{m}(1.5 \mu \mathrm{m}$ in the case of A3), 3 QWs having nominal well and barrier compositions of $\mathrm{In}_{0.02} \mathrm{Al}_{0.22} \mathrm{Ga}_{0.76} \mathrm{~N} / \mathrm{Al}_{0.30} \mathrm{Ga}_{0.70} \mathrm{~N}$. ${ }^{13}$ Samples $\mathrm{A} 1$ and A3 have $2 \mathrm{~nm}$ (sample A2 $4 \mathrm{~nm}$ ) thick QWs. The topmost layer consists of $25 \mathrm{~nm}$ of $\mathrm{Al}_{0.38} \mathrm{Ga}_{0.62} \mathrm{~N}$. The $\mathrm{Al}_{0.35} \mathrm{Ga}_{0.65} \mathrm{~N}$ :Si layers of all three samples have the identical lattice parameters of $a=(3.1575 \pm 0.0007) \AA$ and $c=(5.1184 \pm 0.0003) \AA$ according to reciprocal space maps. This corresponds to compressive strain of $\epsilon_{x x}=-0.013$. The layers above are pseudomorphic to this layer. The samples are sketched in Fig. 1. 
Samples A1, A2
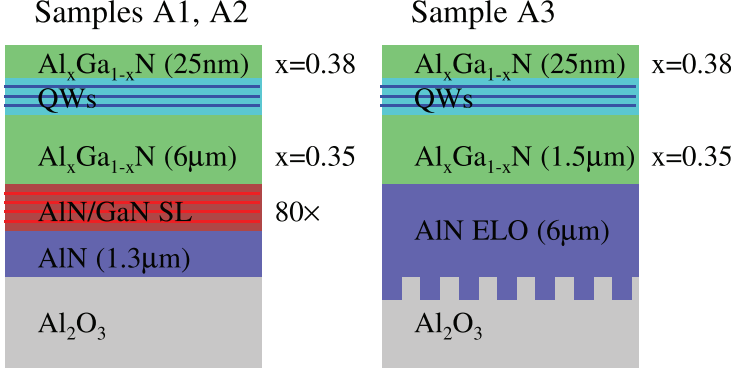

FIG. 1. Schematic of samples $A 1, A 2$, and $A 3$. Quantum well thickness is $2 \mathrm{~nm}$ for $A 1$ and $A 3,4 \mathrm{~nm}$ for $A 2$. Nominal quantum well/barrier compositions are $\mathrm{In}_{0.02} \mathrm{Al}_{0.22} \mathrm{Ga}_{0.76} \mathrm{~N} \mathrm{Al} \mathrm{I}_{0.30} \mathrm{Ga}_{0.70} \mathrm{~N}$. The AIGaN layer below the active region is n-type.

Sample B is very similar to sample A1. The superlattice thickness was changed to $80 \mathrm{~nm}$, followed by a $4.5 \mu \mathrm{m}$ thick $\mathrm{Al}_{0.47} \mathrm{Ga}_{0.53} \mathrm{~N}: \mathrm{Si}$ contact layer. QW/barrier composition is $\mathrm{Al}_{0.40} \mathrm{Ga}_{0.60} \mathrm{~N} / \mathrm{Al}_{0.48} \mathrm{Ga}_{0.52} \mathrm{~N}$, and the top layer consists of $\mathrm{Al}_{0.6} \mathrm{Ga}_{0.4} \mathrm{~N}$. The strain of the $\mathrm{Al}_{0.47} \mathrm{Ga}_{0.53} \mathrm{~N}$ :Si contact layer is known to be slightly compressive on the order of $-0.025<\epsilon_{x x}<-0.001$ while the layers above have the same lattice parameters. ${ }^{10}$ Sample C1, however, bases on a simpler layout. On a sapphire substrate, $1.3 \mu \mathrm{m}$ of AlN was deposited followed by $10 \mathrm{Al}_{0.9} \mathrm{Ga}_{0.1} \mathrm{~N}$ QWs sandwiched between $\mathrm{AlN}$ barrier layers. Sample C2 has the same layer structure but is based again on an AlN ELO buffer identical to sample A3. Both have in-plane lattice parameters of relaxed AlN of $3.112 \AA$.

All samples were investigated by photoluminescence (PL) using $193 \mathrm{~nm}$ excimer $\mathrm{ArF}^{*}$ laser radiation with an excitation density of the order of $1 \mathrm{~kW} / \mathrm{cm}^{2}$. Furthermore, we investigated them by radiation from a synchrotron with much lower excitation density of the order of $1 \mathrm{~W} / \mathrm{cm}^{2}$ in a near-normal incidence geometry. More details about the experiments can be found in Ref. 14 and references therein. All spectra shown in this Letter were recorded at $T=10 \mathrm{~K}$.

First, we discuss the PL results from sample A1 which are shown in Fig. 2. We find a signal at $4.28 \mathrm{eV}$ which is identified as luminescence from the $\mathrm{Al}_{0.35} \mathrm{Ga}_{0.65} \mathrm{~N}$ n-type layer from its energy position, ${ }^{15}$ which does neither match the $\mathrm{Al}_{0.38} \mathrm{Ga}_{0.62} \mathrm{~N}$ contact layer nor the $\mathrm{Al}_{0.30} \mathrm{Ga}_{0.70} \mathrm{~N}$ quantum barriers. At $\approx 3.9 \mathrm{eV}$ a double peak is observed from the QWs. The energy distance between both contributions is around $65 \mathrm{meV}$ not matching a possible explanation as a phonon replica. We assign the low energy contribution to indium-rich regions within the QWs as described in detail below.

The PL signal of sample A1 additionally shows a broad unstructured defect luminescence centered at around $2.65 \mathrm{eV}$. This luminescence band is in the focus of our investigation as we are interested in its origin. All signal bands are visible by both excitation using the $\mathrm{ArF}^{*}$ laser and synchrotron radiation with the same wavelength (Fig. 2). The signal at $4.28 \mathrm{eV}$ attributed to the $\mathrm{Al}_{0.35} \mathrm{Ga}_{0.65} \mathrm{~N}$ n-type layer is strongly reduced in intensity at the synchrotron due to lower excitation density. The low energy shoulder of the QW emission is, however, strongly enhanced in relative signal strength, most likely due to a corresponding low density of states. ${ }^{16}$ PLE spectra employing the defect luminescence and the QW emission as monitor lines are presented in Fig. 2 as well. Several photon energy edges are observed in PLE marking different channels to pump the two luminescence bands investigated.

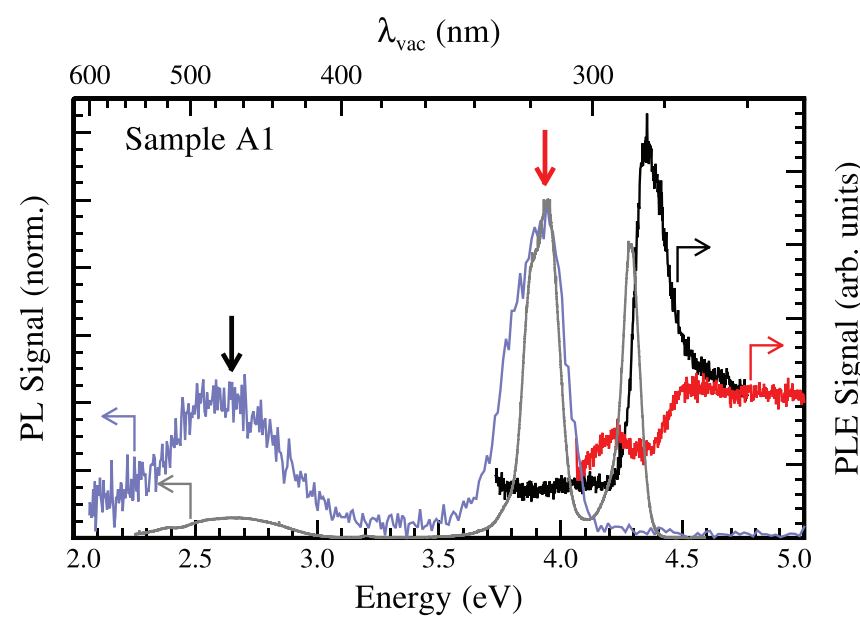

FIG. 2. Photoluminescence (PL) spectra of sample $A 1$, excited by the $A r F^{*}$ laser (grey) and synchrotron radiation (blue curve), both at $193 \mathrm{~nm}$. Photoluminescence excitation (PLE) is monitored once at the broad unstructured defect luminescence at $2.65 \mathrm{eV}$ (black) and once at the quantum well luminescence at $3.94 \mathrm{eV}$ (red curve), both positions are marked by vertical arrows.

The intensity of the QW emission at $3.94 \mathrm{eV}$ increases significantly at excitation energies of $4.13 \mathrm{eV}$ and again at $4.44 \mathrm{eV}$ (red curve). These energies are in good agreement with absorption onsets in $\mathrm{Al}_{x} \mathrm{Ga}_{1-x} \mathrm{~N}$ layers. ${ }^{17}$ Here, one has to keep in mind that the highest valence band has $\Gamma_{7}$ symmetry for $x>0.05 .{ }^{17}$ Absorption processes observed in our (0001) oriented samples are, therefore, most likely related to the next valence band having $\Gamma_{9}$ symmetry. ${ }^{17}$ The step at $4.44 \mathrm{eV}$ is due to the top $25 \mathrm{~nm}$ thick $\mathrm{Al}_{0.38} \mathrm{Ga}_{0.62} \mathrm{~N}$ layer, while that at $4.13 \mathrm{eV}$ belongs to the quantum well's barriers, consisting of $\mathrm{Al}_{0.30} \mathrm{Ga}_{0.70} \mathrm{~N}$. In fact, the experimental energies hint toward slightly higher aluminum concentrations of $x=0.43$ and $x=0.32$, respectively. ${ }^{1}$

In contrast, the broad unstructured defect emission at $2.65 \mathrm{eV}$ is most efficiently pumped if the excitation energy is $>4.30 \mathrm{eV}$ (black curve), corresponding to the $\mathrm{n}$-contact layer having nominally $x=0.35$ again assuming absorption processes related to the $\Gamma_{9}$ valence band. This energy position is in line with an actual aluminum concentration of $x=0.38$; however, it must be clearly less than that of the cap layer. Therefore, this intensity step can be assigned to the $6 \mu \mathrm{m}$ thick n-type $\mathrm{Al}_{0.35} \mathrm{Ga}_{0.65} \mathrm{~N}$ (nominal composition) contact layer below the active region.

Now we compare the excitation and emission spectra of sample A2 (Fig. 3) with the same layer structure as sample A1 but thicker QWs. We find a similar luminescence spectrum but shifted to lower photon energies. However, the low energy shoulder found in the PL spectrum of sample A1 seems to be separated by $\approx 300 \mathrm{meV}$ from the main peak in sample A2 making separate PLE experiments for both contributions feasible. Intensity steps at virtually identical energy positions of 4.38 and $4.00 \mathrm{eV}$ are detected. We again identify both intensity steps with the $25 \mathrm{~nm}$ thick $\mathrm{Al}_{0.38} \mathrm{Ga}_{0.62} \mathrm{~N}$ layer on top and the quantum well's barriers, respectively. In fact, $4.38 \mathrm{eV}$ hints more toward $x=0.42$. For sample A2 the barrier absorption onset is found at lower energy compared to sample A1 being in agreement with a higher net built-in electric field due to the thicker QWs. ${ }^{18}$ Finally, the $3.44 \mathrm{eV}$ 


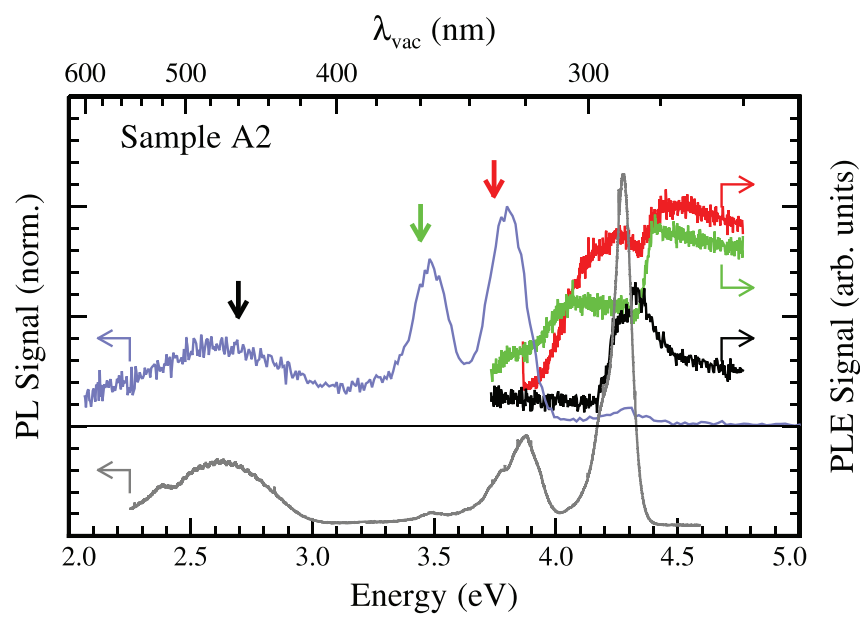

FIG. 3. Photoluminescence (PL) spectra of sample A2, excited by the ArF* laser (grey) and synchrotron radiation (blue curve), both at $193 \mathrm{~nm}$. Photoluminescence excitation (PLE) is monitored at the broad unstructured defect luminescence at $2.70 \mathrm{eV}$ (black), and at the quantum well luminescence bands at $3.75 \mathrm{eV}$ (red curve) and at $3.44 \mathrm{eV}$ (green curve). The positions are marked by vertical arrows.

emission is efficiently excited for photon energies $>3.77 \mathrm{eV}$ marking the absorption edge of the QWs.

From the PLE spectra, it is obvious that both emission contributions at 3.75 and $3.44 \mathrm{eV}$ are from the same layer. We therefore assign the $3.44 \mathrm{eV}$ emission to indium-rich regions of the QWs. ${ }^{19,20}$ Please note that the low energy contribution is only prominent when exciting by synchrotron light, i.e., low excitation density. These excitation conditions also lead to a red shift of the QW emission as expected. ${ }^{21,22}$

The defect emission of sample A2, monitored at $2.70 \mathrm{eV}$, is efficiently excited for photon energies $>4.22 \mathrm{eV}$. Eventually, a second intensity step at $4.31 \mathrm{eV}$ can be seen as well. Corresponding aluminum concentrations are $x=0.35$ and 0.39 , respectively. We therefore assign this emission again to the thick n-type $\mathrm{Al}_{0.35} \mathrm{Ga}_{0.65} \mathrm{~N}$ contact layer below the active region in agreement with our findings from sample A1.

To unambiguously make clear that the defect luminescence around $2.7 \mathrm{eV}$ is not from the superlattice (SL) below the n-AlGaN contact layer (Fig. 1), we further compare results from sample A3 whose active layer is identical to that of sample A1 but the active structure is grown on epitaxially lateral overgrown AlN on patterned sapphire with only a $1.5 \mu \mathrm{m}$ thick $\mathrm{Al}_{0.35} \mathrm{Ga}_{0.65} \mathrm{~N}$ contact layer without superlattice. Results are presented in Fig. 4.

The QW emission, monitored at $3.81 \mathrm{eV}$, is connected with two excitation edges at 4.00 and $4.26 \mathrm{eV}$. The higher energy step is assigned to the nominal $\mathrm{Al}_{0.38} \mathrm{Ga}_{0.62} \mathrm{~N}$ cap layer, hinting toward $x=0.37$, while the lower one is most likely due to absorption in the quantum barriers. The broad defect emission is detected at $2.5 \mathrm{eV}$ and can be efficiently excited for energies $>4.3 \mathrm{eV}$ which is very similar to the case of sample $\mathrm{A} 1$ and thus identified with an origin in the same layer, the n-type $\mathrm{Al}_{0.35} \mathrm{Ga}_{0.65} \mathrm{~N}$ contact layer. Therefore, we identify the defect luminescence visible in PL spectra of the three $\lambda \approx 320 \mathrm{~nm}$ QW structures as originating from the n-type contact layer in all cases.

Now we expand our investigation to shorter wavelength emitters. The results for sample $\mathrm{B}(\lambda \approx 290 \mathrm{~nm})$ show two distinct defect

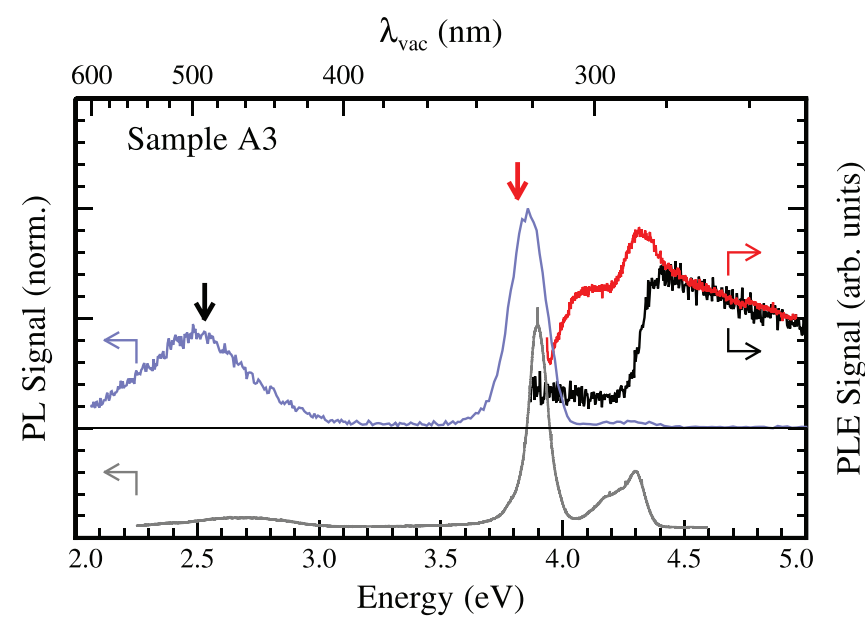

FIG. 4. Photoluminescence (PL) spectra of sample $A 3$, excited by the $\operatorname{ArF}^{*}$ laser (grey) and synchrotron radiation (blue curve), both at $193 \mathrm{~nm}$. Photoluminescence excitation (PLE) is monitored at the broad unstructured defect luminescence at $2.5 \mathrm{eV}$ (black), and at the quantum well luminescence band at $3.85 \mathrm{eV}$ (red curve). The positions are marked by vertical arrows.

luminescence bands (Fig. 5). The band centered at $2.8 \mathrm{eV}$ yields a PLE edge at $4.69 \mathrm{eV}$ corresponding to $x=0.50$ which is in good agreement with the nominal n-type contact layer composition of $\mathrm{Al}_{0.47} \mathrm{Ga}_{0.53} \mathrm{~N}$. We argue that this defect band is the one related to the $\approx 2.5 \mathrm{eV}$ band discussed in samples of series A because it is shifted to slightly higher energy.

In contrast, the second defect band visible around $3.6 \mathrm{eV}$ remains mysterious. We find two PLE steps at 4.50 and $4.73 \mathrm{eV}$; however, these energies correspond to $\mathrm{Al}$ concentrations of 0.43 and 0.52 , respectively. Both these compositions are not intentionally introduced into our samples. Moreover, an absorption contribution around $4 \mathrm{eV}$ remains

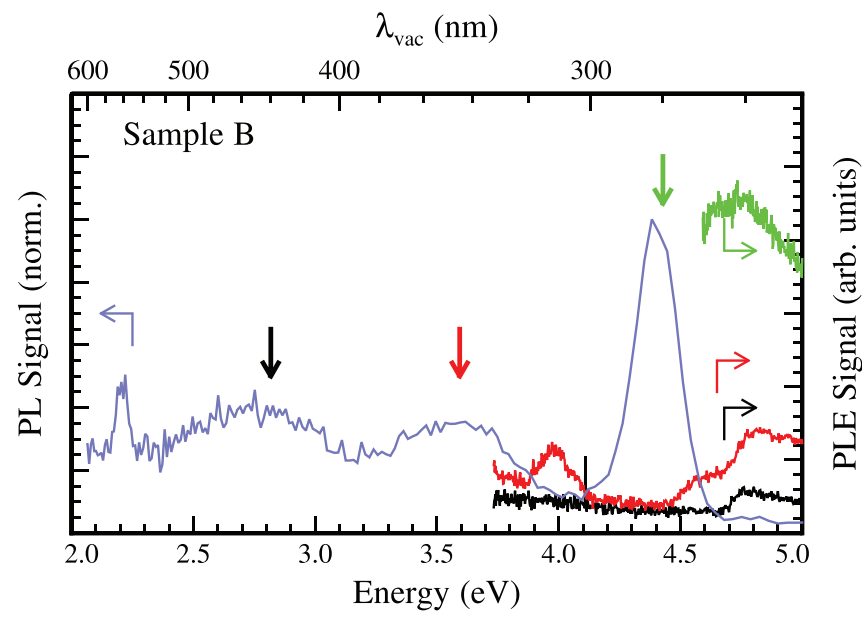

FIG. 5. Photoluminescence (PL) spectra of sample $B$, excited by synchrotron radiation (blue curve) at $193 \mathrm{~nm}$. Photoluminescence excitation (PLE) is monitored at the broad unstructured defect luminescence bands at 2.8 (black) and 3.6 eV (red), and at the quantum well luminescence band at $4.42 \mathrm{eV}$ (green curve). The positions are marked by vertical arrows. 
unclear and so this band resists our attempts to unambiguously assign it to certain layers. Finally, the QW luminescence monitored at $4.42 \mathrm{eV}$ yields a clear but unstructured PLE signal not allowing for further detailed analysis.

Finally, we are looking at the results of two samples of series C, which emit around $\lambda=230 \mathrm{~nm}$. These samples are fundamentally different from series $\mathrm{A}$ and $\mathrm{B}$ as there exists no n-type contact layer. Nevertheless, we find defect luminescence also in these structures. Interestingly, the defect luminescence is found at an energy of $\approx 2.8 \mathrm{eV}$ (Ref. 23) (and a weak shoulder at $3.6 \mathrm{eV}$ at least in sample C1) despite the fact that the layer consists of AlN. For PLE spectra, different longpass filters with cutoff wavelengths at 360 and $280 \mathrm{~nm}$, respectively, were used to suppress second order contributions. The QW luminescence of samples $\mathrm{C} 1$ and C2 (Fig. 6) yields two visible PLE steps in sample C1 at 5.86 and $6.16 \mathrm{eV}$. We identify them as QW absorption and AlN buffer or quantum barrier absorption, respectively, as for this emission wavelength the crystal field splitting causes a strong reduction of TM polarized emission intensity in contrast to the absorption edge of the TE-polarized PLE excitation. ${ }^{12}$ The energy difference between QW luminescence and absorption is in agreement with our earlier results. ${ }^{24}$

The same result is found in sample C2; however, due to lower signal to noise ratio, only the first PLE step is clearly visible, here $\approx 5.9 \mathrm{eV}$. Both defect luminescence contributions investigated $(3.6 \mathrm{eV}$ in sample $\mathrm{C} 1$ and $2.75 \mathrm{eV}$ in sample $\mathrm{C} 2$ ) yield only one clear PLE step

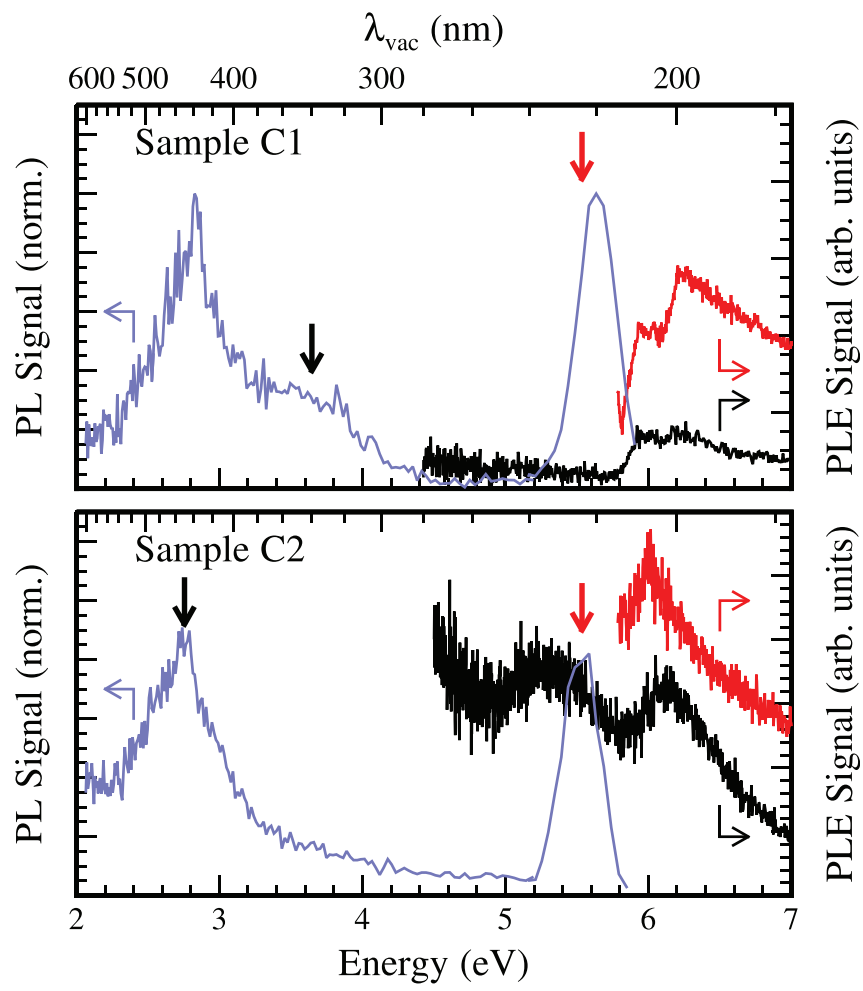

FIG. 6. Photoluminescence (PL) spectra of samples C1 and C2, excited by synchrotron radiation (blue curve) at $193 \mathrm{~nm}$. Photoluminescence excitation (PLE) is monitored at the defect luminescence at 3.6 for sample $\mathrm{C} 1$ and at $2.75 \mathrm{eV}$ for sample C2 (black). The quantum well luminescence band is monitored at $5.54 \mathrm{eV}$ for both samples (red curve). These positions are marked by vertical arrows. which seems to be identical to the QW absorption. The strongly decreasing PLE efficiency for increasing photon energies $>6.4 \mathrm{eV}$ further corroborates this interpretation because such light penetrates only a few $\mathrm{nm}$ into the sample. Because photon energies above $\approx 5.9 \mathrm{eV}$ already suffice to pump the defect luminescence, we conclude that the defect luminescence in series $C$ originates from the QWs rather than from the AlN buffer or barrier layers.

According to photoluminescence data of undoped ${ }^{25}$ and Si doped AlGaN layers, ${ }^{26}$ this defect luminescence was observed before at similar energy positions taking into account the layer composition. There, an assignment to cation vacancy complexes was put forward.

In summary, our synchrotron-based PLE study of defect luminescence in AlGaN UV LED structures revealed that the dominating defect luminescence band, that is even visible under $193 \mathrm{~nm}$ excitation with a low penetration depth, originates in the n-type AlGaN contact layer below the active region if such a layer is present. Only for heterostructures emitting at extremely short wavelengths, we find defect luminescence from the QWs themselves. All these findings allow further optimization of the relevant defect-containing layers to increase the efficiency of future UV-LEDs.

A part of this research was carried out at the light source DORIS III at DESY. DESY is a member of the Helmholtz Association (HGF). We would like to thank A. Kotlov for excellent assistance in using beamline I at DESY. This work was partially supported by the Federal Ministry of Education and Research (BMBF), under Contract No. 13N9933 and Berlin WideBase initiative under Contract No. 03WKBT01D and the German Research Council within the Collaborative Research Center 787.

\section{DATA AVAILABILITY}

The data that supports the findings of this study are available within the article.

\section{REFERENCES}

${ }^{1}$ K. C. Anyaogu, A. A. Ermoshkin, D. C. Neckers, A. Mejiritski, O. Grinevich, and A. V. Fedorov, J. Appl. Polym. Sci. 105, 803 (2007).

${ }^{2}$ J. Hodgkinson and R. P. Tatam, Meas. Sci. Technol. 24, 012004 (2013).

${ }^{3}$ M. A. Würtele, T. Kolbe, M. Lipsz, A. Külberg, M. Weyers, M. Kneissl, and M. Jekel, Water Res. 45, 1482 (2011).

${ }^{4}$ A. Khan, K. Balakrishnan, and T. Katona, Nat. Photonics 2, 77 (2008).

${ }^{5}$ M. Kneissl, T.-Y. Seong, J. Hang, and H. Amano, Nat. Photonics 13, 233 (2019).

${ }^{6}$ Z. Bryan, I. Bryan, J. Xie, S. Mita, Z. Sitar, and R. Collazo, Appl. Phys. Lett. 106, 142107 (2015).

${ }^{7}$ D. Jin, R. Connally, and J. Piper, J. Phys. D: Appl. Phys. 39, 461 (2006).

${ }^{8}$ M. Meneghini, D. Barbisan, Y. Bilenko, M. Shatalov, J. Yang, R. Gaska, G. Meneghesso, and E. Zanoni, Microelectron. Reliab. 50, 1538 (2010).

${ }^{9}$ A. Mogilatenko, J. Enslin, A. Knauer, F. Mehnke, K. Bellmann, T. Wernicke, M. Weyers, and M. Kneissl, Semicond. Sci. Technol. 30, 114010 (2015).

${ }^{10}$ J. Enslin, F. Mehnke, A. Mogilatenko, K. Bellmann, M. Guttmann, C. Kuhn, J. Rass, N. Lobo-Ploch, T. Wernicke, M. Weyers, and M. Kneissl, J. Cryst. Growth 464, 185 (2017).

${ }^{11}$ A. Mogilatenko, V. Küller, A. Knauer, J. Jeschke, U. Zeimer, M. Weyers, and G. Tränkle, J. Cryst. Growth 402, 222 (2014).

${ }^{12}$ C. Reich, M. Feneberg, V. Kueller, A. Knauer, T. Wernicke, J. Schlegel, M. Frentrup, R. Goldhahn, M. Weyers, and M. Kneissl, Appl. Phys. Lett. 103, 212108 (2013).

${ }^{13}$ J. Enslin, T. Wernicke, A. Lobanova, G. Kusch, L. Spasevski, T. Teke, B. Belde, R. W. Martin, R. Talalaev, and M. Kneissl, Jpn. J. Appl. Phys., Part 1 58, SC1004 (2019). 
${ }^{14}$ G. Zimmerer, Radiat. Meas. 42, 859 (2007).

${ }^{15}$ B. Neuschl, J. Helbing, M. Knab, H. Lauer, M. Madel, K. Thonke, T. Meisch, K. Forghani, F. Scholz, and M. Feneberg, J. Appl. Phys. 116, 113506 (2014).

${ }^{16}$ F. Römer, B. Witzigmann, M. Guttmann, N. Susilo, T. Wernicke, and M. Kneissl, Proc. SPIE 10912, 109120D (2019).

${ }^{17}$ M. Feneberg, M. Winkler, J. Klamser, J. Stellmach, M. Frentrup, S. Ploch, F. Mehnke, T. Wernicke, M. Kneissl, and R. Goldhahn, Appl. Phys. Lett. 106, 182102 (2015).

${ }^{18}$ I. Brown, I. Pope, P. Smowton, P. Blood, J. Thomson, W. Chow, D. Bour, and M. Kneissl, Appl. Phys. Lett. 86, 131108 (2005).

${ }^{19}$ S. F. Yu, S. J. Chang, R. M. Lin, Y. H. Lin, Y. C. Lu, S. P. Chang, and Y. Z. Chiou, J. Cryst. Growth 312, 1920 (2010).

${ }^{20}$ G. Kusch, J. Enslin, L. Spasevski, T. Teke, T. Wernicke, P. R. Edwards, M. Kneissl, and R. W. Martin, Jpn. J. Appl. Phys., Part 1 58, SCCB18 (2019).
${ }^{21}$ E. Kuokstis, J. W. Yang, G. Simin, M. A. Khan, R. Gaska, and M. S. Shur, Appl. Phys. Lett. 80, 977 (2002).

${ }^{22}$ S. Watanabe, N. Yamada, M. Nagashima, Y. Ueki, C. Sasaki, Y. Yamada, T. Taguchi, K. Tadatomo, H. Okagawa, and H. Kudo, Appl. Phys. Lett. 83, 4906 (2003).

${ }^{23}$ It should be noted that the $2.8 \mathrm{eV}$ defect bands in Fig. 6 are likely overlaid by a second order diffraction peak of the QW luminescence despite using longpass edge filters with a cutoff of $225 \mathrm{~nm}$. Therefore, the line shapes of the defect bands should not be relied upon.

${ }^{24}$ M. Feneberg, M. Röppischer, C. Cobet, N. Esser, B. Neuschl, T. Meisch, K. Thonke, and R. Goldhahn, Appl. Phys. Lett. 99, 021903 (2011).

${ }^{25}$ K. B. Nam, M. L. Nakarmi, J. Y. Lin, and H. X. Jiang, Appl. Phys. Lett. 86, 222108 (2005).

${ }^{26}$ N. Nepal, M. L. Nakarmi, J. Y. Lin, and H. X. Jiang, Appl. Phys. Lett 89, 092107 (2006). 